of the effort to measure the patient's pelvis of usage on the Continent of Europe, and which will when possible, and when this is not practicable to render more comprehensible the mechanism of labor. estimate the comparative sizes of the head of the I refer to the designation of two positions only for child and the mother's birth-canal. In this the pro- each presentation, anterior or posterior rotation befession must educate its patients, and this can be ing designated, as the case may be. Second, the imdone only if methods of examination are conducted portance of pelvimetry and of the comparative estiwithout exposure, without violence, and in a kindly mation of the sizes of the head and the pelvis is and skilful manner. It is my custom to teach students to examine the pelvis, diagnosticate the position of the child and its presentation, and ascertain whether the head is likely to enter the pelvis readily, while the patient remains covered with one thickness of linen. We can no longer comfort ourselves with the remark that American-born women rarely have contracted pelves; this statement is not strictly true, and the large number of foreigners coming to our country show frequent examples of varying degrees of pelvic malformation. The skilful obstetrician, by his knowledge, avoids prolonged and disastrous labors, and wuch good results are impossible without a skilful examination of the pregnant patient. If a large head be detected at the brim of the pelvis, scarcely able to enter, and showing a disposition to rotate posteriorly, it will be found better practice in many cases to perform the conservative Crsarean section, saving the lives of mother and child, rather than subjecting the child's life to great risks and exposing the mother to serious injury in delivery.

I desire, secondly, to draw attention to the efficacy of posture in favoring rotation of the occiput when the head has entered the pelvis. Whether it be that the patient lies upon the side toward which the occiput is pointing, or whether she inclines the pelvis forwards, I am convinced from observation that posture is a valuable adjunct in the conduct of such cases. I desire also to criticise that method of examination consisting in the introduction of but a portion of one or two fingers in the effort to make an accurate diagnosis of the location of the occiput, and to favor its anterior turning. The practitioner should prepare himself to apply the forceps if necessary, and then anæsthetize his patient to obstetric ancesthesia, preferable with chloroform; he should introduce so much of the hand as may be necessary to make an accurate examination of the entire vertex. In the intervals between the pains he will be able to favor anterior rotation, and when he has thus brought the vertex in front of the middle of the pelvis, without removing the hand the forceps may be applied and the labor terminated.

Third. The forceps is often applied too soon, thus neglecting one important factor in anterior rotation, namely, the resistance of the pelvic floor. If the forceps be applied before the head has had an opportunity to rotate upon the pelvic floor, its posterior turning is often favored by the instrument rather than its anterior rotation. On the other hand, the forceps is often applied too late, when flexion has become impossible by reason of the persistence of partial extension, the head becoming impacted upon the pelvic floor in this unfavorable position. The life of the child has frequently been lost in such cases before the final effort at delivery is made, and when such is the case craniotomy is often the only rational procedure.

In conclusion, I would urge the following as points of importance: First, the adoption of the simple nomenclature already stated, which has borne the test paramount; by the second of these I mean the careful estimation as to the degree of engagement of the head, and if the head has not engaged, pressing it gently into the pelvis by supra-pubic pressure, the patient being, if necessary, partially anæsthetized. Third, when the head is proportionate in size to the pelvis, and lingers upon the pelvic floor by reason of failure in expulsive force, the child's life and also the mother's safety being in danger, the forceps should invariably be used with axis-traction. The forceps should be used in accordance with the possibilities of the case, and that form of instrument should be selected that was intended for such possibilities. Whenever practicable, forceps designed to be so applied should be accurately placed upon the sides of the child's head, axis-traction made, the head and the forceps rotating together anteriorly. When such accurate apposition is impossible, forceps modelled for application to the sides of the pelvis should be employed with axis-traction, the forceps making as little pressure as possible upon the head, the blades being relaxed after each traction so that rotation anteriorly may occur between the blades. Fourth, a conservative Cæsarean section may be indicated if a living child, with large, firmly ossified head, presents with a posterior rotation of the occiput, the head failing to descend into the pelvic cavity; craniotomy may be indicated if such a child has perished during its entrance in to the pelvis.

\title{
THE IMPORTANCE OF SURGICAL TREAT- MEN'T FOR LACERATION OF THE CERVIX UTERI.
}

Read in the Section of Obstetries and Diseases of Women, at the Fortythird Annual Meeting of the American Medical Association, held in Detroit, Mich., Juue, 1892.

BY AUGUSTUS P. CLARKE, A.M., M.D., OF CAMBRIDGE, MASS.

The opportunities now afforded to the gynecologist for studying the effect in any case of laceration of the cervix uteri leave but little doubt that treatment is a most important subject for consideration. Experience has, however, demonstrated that the local application of the various agents which from time to time have been suggested as being remedial or beneficial is at best but a temporary expedient. Whenever a laceration occurring at the cervix extends through the internal and external muscular tissue, the mucous coat lining the canal suffers materially from the violence. The plicæ palmatæ which have been described under the term arbor-vitæ undergo serious disturbance in their relation to the other tissues with which they are connected. This condition often leads to congestion, thickening and to induration of the parts involved and to more or less hypertrophy and malnutrition of the higher uterine segments, and to changed relation and to displacement of the lower cervical zone. When laceration occurs at the cervix it is not only that the muscular and the mucous structures are injured but it is also that the mucous glands which so freely abound in 
the uterine canal become disturbed in their normal functional activity. It is especially the cervix uteri about the arbor vita that the mucous follicles which when in a healthy condition afford only a moisture for the maintaining of their function, give rise to the formation of an altered, perverted or diseased secretion. The arteries and arterials entering into these structures often become preternaturally developed or enlarged; there will often be found a greater interlacing or anastomosing of these vascular structures. This condition may lead to more or less local odema, which the venules and lymphatics will fail to overcome. The structure of the uterine nerves, particularly those derived from the hypogastric and sacral plexuses, become so deeply involved that not only the parts in immediate contact with the torn or injured surfaces become the source of much trouble but all the tissues forming the uterine body may continue so heavily congested and become so thickened, indurated and globular as to be recognized only as that condition which has so aptly been termed, subinvolution of the uterus.

The treatment best adopted for the relief of the suffering which occurs in every such case, according to my experience, is that afforded by surgical measures. The history of the following case illustrates in some measure the importance of such treatment.

Mrs. C., aged thirty-six years, descended from good stock, and was originally of sound constitution and in good health. Her embonpoint, though fair, was not excessive. She was a sextipara. The eldest child was eleven years old and the youngest three years. At the time I was first called, Dec. 14,1891 , there had been a most profuse uterine hæmorrhage. On my arrival I found that the patient was blanched; her pulse exceedingly weak and easily compressible. The cardiac sounds were feeble and gave indication that there was some dilatation and perhaps fatty degeneration of that organ. The patient had, for the most part, been regular in her catamenial flow, though she had suffered at times from unusual loss of blood. There was no evidence in the history of the case to show that the patient was suffering from the effects of abortion or that she was pregnant, or at any time had ever suffered from a miscarriage. A few days immediately preceding the date of my attendance she had been doing some extra household work and had attempted to lift some heavy articles of furniture. This may have been the exciting eause of the hemorrhage. Taginal examination revealed that the cervix was patulous, that it was hard and unyield. ing, and that multiple cervical laceration had evidently long existed. There was also an old perineal laceration which might have contributed somewhat to her inconvenience. By tamponading with iodoform gauze, the hæmorrhage was brought under immediate control. Next day a thorough vaginal examination showed that there was subinvolution; the depth of the uterine cavity was six and a half inches; there was also cicatricial ectropium of the cervix to an unusual degree. For some days the use of the tampons was continued, though there was no further hamorrhage. The patient subsequently suffered severely from facial and super-orbital neuralgia, sometimes on the left side, and at other times on the right. The patient also suffered from sciatica appearing on the right side; the occurrence of this affection had, from time to time, heretofore added much to her illness. Full and repeated doses of mor phia and of other opiates often afforded her marked relief stimulants were well borne and were frequently required to overcome the narcotic effect of the soporifics.

Dec. 22. - The patient suffered from a severe attack of gas tralgia, which yielded onIy to morphia hypodermatically administered. Under careful regulation of diet, and with the judicious use of stimulants the patient from this time forward gradually improved, though she was kept in bed in consequence of the local inconvenience from which she suffered every time she stood or was in the erect position.

Feb. 3.-With the assistance of Dr. A. H. Tuttle, the patient was etherized and placed on the table for surgical treatment. All details of the operation were carried on under strict antiseptic precautions. The uterine cavity still measured six and one half inches. This was first curet- ted; after this the cervix was repaired. Aseptic animal sutures were employed. The mucous tissue of the lacerated perineum was then dissected up as far as the sulcus on each ide; coaptation of the torn surfaces of the perineal tissue was effected by the employment of the same kind of aseptic animal suture. The deep sutures were first inserted, each tissue was brought together in its proper order, last of all the edges were brought together by the buried suture and the parts united were sealed with collodium and iodoform. The whole was protected by dressings to the cervical, vaginal and perineal tissues. The patient rallied well from the ether, though more than the average quantity had to be used to overcome all rigidity of the genital tract. The bladder was catheterized at regular intervals to prevent the repaired tissues from becoming contaminated by the discharge of the urine. The patient suffered very little from the effects of the operation; there was no increase of temperature. She experienced some trouble from a return of sciatica, though this occurred on the left instead of the right side. Neuralgia occurring in the face and in other parts was at intervals complained of. She took nourishment and stimulants freely until the evening of the twelfth of February, when she began to suffer from dyspnoea; the pulse at that time became irregular, and the heart's action at intervals was labored. Though the patient was able to continue the use of nourishment and stimulants she died during the evening of the fourteenth. Autopsy twelve hours after death.

On opening the chest the heart was found to have undergone more or less fatty degeneration; both ventricles were somewhat dilated. The left ventricle contained an antemortem clot. The lungs were congested. The liver gave indication that it was undergoing also fatty degeneration ; the spleen, however, was normal. The right kidney was congested and was darker than normal; the left one showed that marked organic changes had for some time been going on, and that it was approaching to a condition of parenchymatous inflammation. At the cervix uteri, where the lacerated tissue had been brought together by the operation for repair. the parts were in a healthy condition; the line of union had nearly healed. The uterine canal also presented a healthy surface; it showed that all the fungoid granulations had been removed by the curetting. The uterus showed that there had taken place a rapid retrograde metamorphosis of tissue, for the canal itself measured now scarcely four inches in depth. There had already taken place a strong line of union at the coapted parts in the torn perineum. There was no indication, about the parts, that any sepsis had occurred. The autopsy, which had been carefully conducted, did not give the slightest indication that there had been any septicemia or that other morbid process had occurred as the result of the surgical measures undertaken for the patient's relief. The autopsy further showed that there was no pel. vic or uterine tumor and nothing to indicate the existence of a cancerous development, though such had been believed to have existed by some of her previous medical advisors.

In view of all the facts connected with the case it seems fair to conclude that the cause of the death was owing to the excessive loss of blood which occurred immediately previous to my first visit. This loss of blood necessitating the horizontal position which had to be so long assumed must have hastened the degenerative changes that had before been insidiously developing. It is also fair to infer that had the operation for her relief been instituted before the lapse of so many years, during which she had suffered from hæmorrhage and from other untoward symptoms, her life might have continued a much longer duration. In another case of cervical laceration occurring during labor the patient suffered much from endocervicitis and from uterine hæmorrhage. After coming under my care she had intended to submit to an operation but had delayed the matter owing to a succession of cases of illness that appeared in her family. The patient suffered much from the subinvolution and from the local inconvenience whenever she travelled or was about her house. She had grown stout, but her flesh was soft from a lax habit of the body. Auscultation revealed that though there was no distinct cardiac murmur the 
two sounds were weak and that dilatation and fatty degeneration had begun to take place. Another severe uterine hæmorrhage so prostrated her that she had to be confined for some weeks to her bed. She suddenly died from degenerative changes occurring in the cardiac tissue. In this case there can be no doubt that had surgical measures been adopted for her relief before she had sustained so mich loss of blood, the fatty degeneration of the heart's structure would not have been accelerated by the influences of the recumbent position which sle also, from time to time, was frequently enforced to take. In cases in which the disturbance is greatest at the cervix uteri operation for repair will often yield most favorable results. In such cases it is surprising to see how speedily the thick and indurated tissue at the cervix softens and relaxes under the influence of the stimulus imparted by operative interference. The venules and lymph vessels which seemingly, had long since lost or suspended their function, take on an almost immediately, for effecting this accomplishment, renewed activity. In a case of cervical laceration to which $I$ was recently called, there was but little that could be expected to be achieved by the adoption of surgical measures on account of the unusual hypertrophy of the tissues, which had taken place, and also on account of the exhausted condition of the patient. The operation however, was undertaken. I was happily surprised to find that I had succeeded in effecting so much toward the reduction of the induration and toward bringing about restoration of the cervix. In cases of cervical laceration before the structures become indurated or cicatrized the ectropium or eversion of the tissues of the os uteri may be the chief indication for which surgical treatment is required. Eversion, when present to any great extent, almost always gives rise to much local suffering, especially whenever the patient assumes the erect position. Such a condition of the cervix is sometimes the cause of sterility; it often interrupts the marital relation. In a case to which I was called in consultation some two and a half years ago the tissues of the os uteri so projected forward as to give the impression to the medical attendant, when the examination was made without the help of the speculum, that a foetus at the term of four months or more, had engaged the cervical canal. This patient had been the mother of four children, during the birth of the last of which laceration of the cervix occurred. As a consequence of this injury, repeated hæmorrhage had been a troublesome factor; this had often come on without apparent connection with the influence of the catamenial flow. This case under temporizing treatment had dragged on for upwards of three years. A resort to trachelorrhaphy was followed with marked amelioration. Emmet, as it is well known, long since expressed his belief that nearly all cases of uterine epithelioma or cauliflower growth have their exciting cause or origin in laceration of the cervix uteri. The cancerous development according to Emmet, arises from prevented nutrition in nature's attempt to repair the injury.

Professor Graily Hewitt, of London, and other eminent authors have expressed their opinion that injury to the cervix by labor, is the predisposing cause of uterine cancer. In a case which has recently come under my care the history showed that there had been a cervical laceration dating back some ten years. The patient's age was forty-six years; she was a multipara. There had been considerable in. duration and eversion. Nothing from the history could be learned that cancer had ever appeared in her family. The patient,for several months previous to the manifestation of cancer in the cervix uteri, had dwelt in a family in which two cases of cancer. ous disease had occurred. In another case to which I was called, the patient was a primipara; her age was twenty-nine years. There was no evidence that malignant disease in either branch of her family was hereditary or that in either of them a case of such disease had ever appeared. One year before she had experienced the initial symptoms of cancer of the cervix she had devoted much time in the care of a friend who was suffering from cancer of the breast. She had incurred a cervical laceration during the labor which took place five years before. She experienced considerable inconvenience from the effects of the laceration, and had from time to time received local treatment; no operation, however, for repair of the cervix was ever undertakon. In many cases of laceration of the cervix induration that takes place is limited to an exceedingly small section; the eversion may give but little trouble. In such cases there may have been no arrest of the action of the absorbents that are engaged in the removal of the provisional material incident to pregnancy. In some cases of this class, it would seem that the occurrence of laceration increases the activity of the absorbents, or at least helps to expose them to the agency of the materies morbi or to that of the disease germs, which at any time may gain admission into the vaginal introitus. As more evidence has of late been adduced tending to show that cancer in its various manifestations is a contagious ${ }^{1}$ affection a much stronger plea than heretofore, can now be offered in support of the advantages to be derived by the resort to the operation for repair of the cervix in. which laceration has occurred, though it be of a minor grade.

\section{THF MANAGEMENT OF CANCER OF THE UTERUS, COMPLICATED BY PREG- NANCY, WITH REPORT OF A CASE.}

Read in the Section of Obstetries and Diseases of Women, at the Fortythird Annual meeting of the American Medical Association, held at Detroit, June, 1892

\section{BY A. VANDER VEER, MI.D.,}

PROFESSOR OF DIDACTIC, ABDONINALAND CLINICAL SURGERY, ALBANY MEDICAL COLLEGE, ALBANY, N. Y.

Pregnancy and uterine cancer are conditions, fortunately, rarely associated. Winckel saw eight cases of cancer of the cervix uteri in a total of fifteen thousand cases of pregnancy. Stratz saw twelve in seventeen thousand nine hundred cases. Sutugin saw two in nine thousand, or, in other words, out of nearly forty-two thousand cases of pregnancies, observed in three great obstetric clinics, only twentytwo cases of cancer of the uterus occurred as a complication, roughly, one case in every two thousand cases of pregnancy. Like all statistics these have only a relative value. Consulting obstetricians see relatively more cases than do general practitioners, and apparently see as diverse results of treatment. For example, the much-to-be-lamented late Dr. For1891

Observations of M. Guelliot and M. Arnaudet. L' Chion Medicale, 